IP Periodica Polytechnica

Transportation Engineering

43(3), pp. 111-119, 2015

DOI: 10.3311/PPtr.7599

Creative Commons Attribution (i)

RESEARCH ARTICLE

\section{Free Speed Modeling for Urban Arterials - A Case Study on Delhi}

\author{
Amudapuram Mohan $\mathrm{Rao}^{1}, \mathrm{~K}$. Ramachandra $\mathrm{Rao}^{2 *}$
}

Received 04 July 2014; accepted after revision 30 October 2014

\begin{abstract}
Free-flow speed is an important characteristic for capacity and level-of-service analysis of urban arterials. The objective of this study is to develop models for estimating free-flow speed. Many generic factors like weather, environment, vehicles, roadway characteristics, driver and traffic streams either singly or in combination influence the free flow speed. The quantitative measures of these factors are desirable for reliable free flow speed measurement and system design. In this paper an attempt has been made to identify the factors which affect the free flow speed. Data collection was done on the midblock segments of urban arterials in Delhi. Further, the geometric properties of the arterial were collected by dividing the given stretch of the road into smaller segments. The factors such as, total number of vehicles, major intersections, access points and length of the sections seem to have a significant influence on free flow speeds.
\end{abstract}

\section{Keywords}

Free speed, friction factors, traffic flow characteristics, data processing

\footnotetext{
${ }^{1}$ Central Road Research Institute, New Delhi 110025

${ }^{2}$ Department of Civil Engineering, IIT Delhi,

Hauz Khas, N. Delhi - 110 016, India

${ }^{*}$ Corresponding author, e-mail: rrkalaga@civil.iitd.ac.in
}

\section{Introduction}

Free flow speed can be defined as the desired average speed adopted by the driver when not restricted by other vehicles in the stream under given set of road conditions (HCM, 2010; Polgár et al., 2013; Tettamanti and Varga, 2014). Other definitions vary depending on the context or application. Two important definitions are given here. Firstly, the free-flow speed on an urban street is the speed that a vehicle travels under low volume conditions when all the signals on the urban street are green for the entire trip. When vehicle interaction and traffic control are not factors, the speed chosen by the average driver is referred to as the free-flow speed (FFS). Secondly, FFS is the average speed of the traffic stream when traffic volumes are sufficiently low that drivers are not influenced by the presence of other vehicles and when intersection traffic control is not present or is sufficiently distant as to have no effect on speed choice (HCM, 2010). Also, the volume of traffic is an important factor, in influencing the free flow conditions.

Theoretically, FFS should be the speed at which the flow is zero. To overcome this difficulty, it is generally measured at very low flow levels. Further, FFS is very important in traffic stream analysis for incidents and bottlenecks and hence the factors influencing its value should be studied carefully for understanding the traffic behaviour and this analysis also helpful in sensitivity analysis. Three principal factors of (a) roadway geometry and condition (Baruzzi et al., 2008; Bassani et al., 2012) (b) driver's attributes and (c) environment, have been reported to influence the values in the American urban traffic streams and highways (Lamm et al., 1990). In addition to above the pavement roughness also have a significant influence on free flow speeds (Wang et al., 2014). Driver's attributes and vehicle characteristics are also one of the major factors in the estimation of urban free flow speed. Younger drivers, level of passenger occupancy, age of vehicles and trip purpose have impacted higher values on the speed while horizontal/vertical alignments and parked vehicles along the road impacted negatively on free flow speeds (Dowling et al., 1997). This study presented a detailed analysis of the effect of human factors on the free flow speeds in the context of person-machine control 
system. Thus it is evident that free flow speeds depends on the variables described under three broad categories: driver, road geometry and environment. Moreover, when the traffic and environment conditions as in Asia (China, India and Indonesia etc.) prevail, it is essential to revisit the existing free flow speed estimation methods.

Rest of the paper is organized as follows. Section 2 presents the literature review. Sections 3 and 4 give the details of the study area and the data collection. Sections 5 and 6 present traffic characteristics and free flow speed from field data collection. Sections 7 and 8 present the factors affecting the free flow speed and models for predicting it. Summary and conclusions are presented in Section 9.

\section{Literature Review}

In addition to the free flow speed description given previously, other definitions using vehicle headway are discussed here. A car is assumed as free flowing when it has headway of $8 \mathrm{~s}$ or more to the vehicle ahead and $5 \mathrm{~s}$ or more to the vehicle behind in the same traffic lane (HCM, 2010). The free-flow speed for a passenger car is typically $10-20 \%$ higher than that for other types of light vehicles (China HCM 1999). Further, the free speed is the average speed of unobstructed vehicles over a road segment at which drivers feel comfortable travelling, under the physical, environmental, and traffic control conditions existing on an uncongested section of road segment (IHCM, 1996). The free flow speed is dependent on the spacing of the intersections, speed limit, median type, lane location and vehicle type (Tseng et al., 2013). Because free flow speed is affected by many factors ( $\mathrm{Ng}$ and Small, 2012; Török, 2013), it is obvious that an appropriate and robust model for predicting free flow speed has to take into account numerous independent variables related to geometrics, traffic, and signalization. Some of the free flow speed models available in various HCMs are explained in detail here.

\subsection{HCM 2010}

The recently proposed model in Highway Capacity Manual (HCM, 2010) for predicting base FFS is given in Eq. (1)

$$
S_{f}=\left(25.6+0.47 S_{p l}+f_{c s}+f_{A}\right) f_{L}
$$

where

$$
\begin{aligned}
& S_{f}=\text { Base FFS } \\
& S_{p l}=\text { Speed limit } \\
& f_{c s}=\text { Adjustment for cross section } \\
& f_{A}=\text { Adjustment for access points } \\
& f_{L}=\text { Adjustment Factor for segment length }
\end{aligned}
$$

\subsection{Indonesia HCM (IHCM, 1993)}

Indonesian HCM presents the plots relating SFFS with various traffic characteristics. The travel speeds are related to the FFS through an equation (Eq. (2)) The factors considered for free speed as per the IHCM are listed below;
1. Carriageway width (m)

2. Pedestrian movement

3. Vehicles stopping on the roadway,

4. Vehicles turning into or out of the segment and

$$
V=\left(V_{0} / 2\right)\left[1+(1-D S)^{0.5}\right]
$$

where

$$
\begin{aligned}
& \mathrm{C}=\text { Capacity }(\mathrm{pcu} / \mathrm{h}) \\
& \mathrm{Q}=\text { actual flow }(\mathrm{pcu} / \mathrm{h}) \\
& \mathrm{DS}=\text { degree of saturation }(\mathrm{Q} / \mathrm{C}) \\
& \mathrm{V}=\text { Speed }(\mathrm{km} / \mathrm{h}) \\
& V_{0}=\text { Free flow speed }(\mathrm{km} / \mathrm{h})
\end{aligned}
$$

\subsection{China HCM (CHCM, 1996)}

FFS for light vehicles is used as a measure of performance in China HCM. The FFS is estimated using the Eq. (3) given below;

$$
F V=\left(F V_{0}+F V_{C W}+F V_{C L A S S}\right) F F V_{L U}
$$

where

$F V=$ Free flow speed for light vehicle at actual conditions $(\mathrm{km} / \mathrm{h})$

$F V_{0}=$ Base Free flow speed for light vehicles $(\mathrm{km} . \mathrm{h})$

$F V_{C W}=$ Adjustment for carriageway width $(\mathrm{km} / \mathrm{h})$

$F V_{C L A S S}=$ Adjustment for road function and road class

$F F V_{L U}=$ Adjustment factors for land use characteristics (side friction and road side development).

The adjustment factor for land use characteristics $F F V_{L U}$ is different for township roads and for other road segments. The base free flow speed $F V_{0}$ as well as the adjustments $F V_{C W}$ and $F V_{\text {CLASS }}$ are the same for both types of segments.

All the HCMs provide methods to estimate the free-flow speed as a function of the physical (geometric) and Operational/traffic characteristics of the facility. The factors considered are varied for different countries; an attempt was made in this paper to find the impact of various factors on free flow speed and subsequently modelling the free flow speed for urban arterials in India.

\section{Study Area}

The National Capital Territory (NCT) of Delhi is spread over an area of $1484 \mathrm{~km}^{2}$ of which $783 \mathrm{~km}^{2}$ is designated as rural and $700 \mathrm{~km} 2$ urban. The road network in Delhi is $33,198 \mathrm{~km}$ as on March 2012 having $1922 \mathrm{~km}$ of road length per $100 \mathrm{~km}^{2}$; Delhi has the highest road densities in India. Road network accounts for about $21 \%$ of the total area, which is above the national average of 12 to $15 \%$ for urban areas. Delhi has been facing traffic congestion. The reasons attributed for these conditions are the ever increasing number of vehicles in Delhi close to 7.45 million (Economic Survey of Delhi, 2012). Delhi road network is shown in Fig. 1. Inner Ring Road one of the principal arterial 


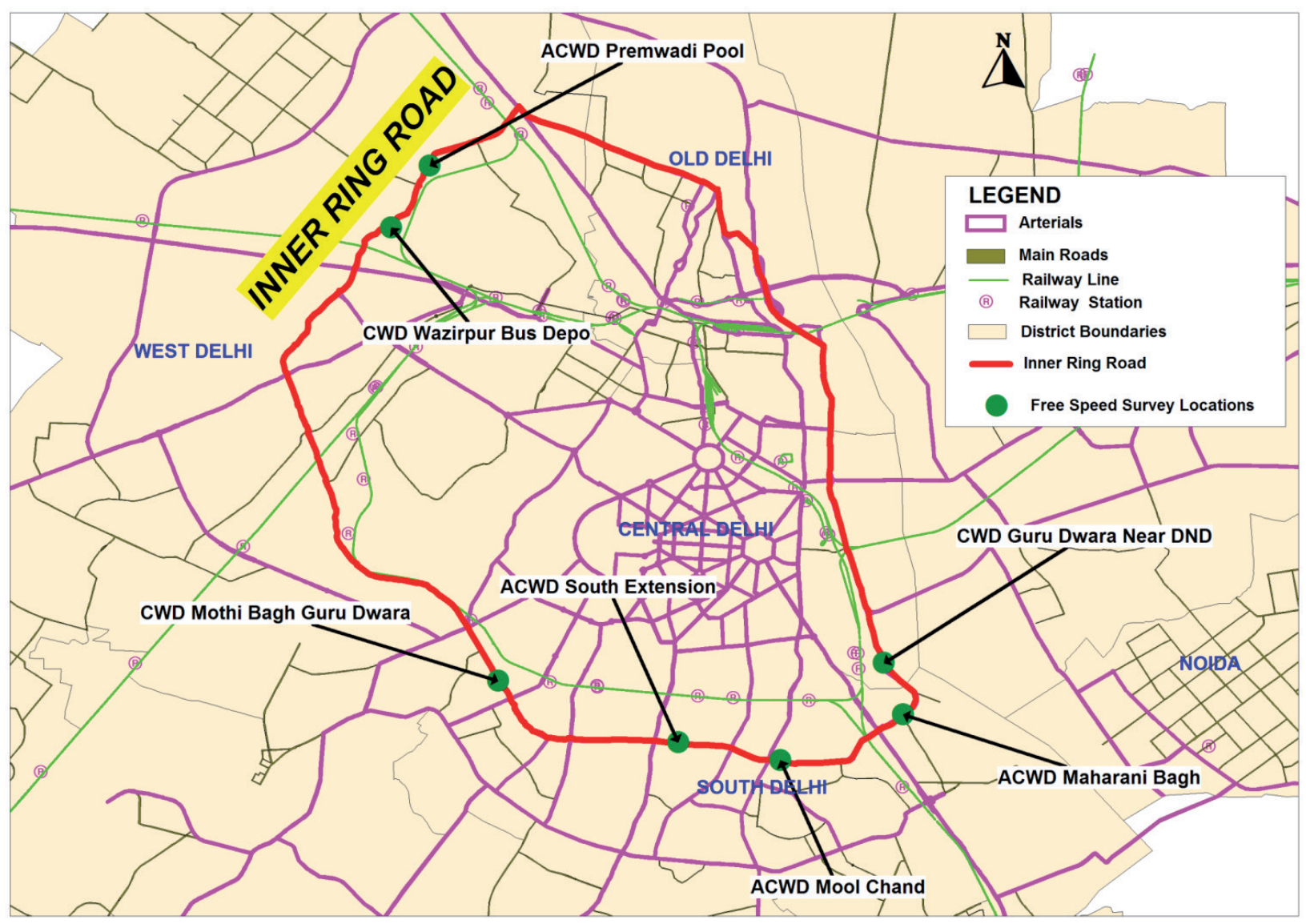

Fig. 1 Corridors selected for study

(CWD - Clockwise Direction; ACWD - Anti-Clock Wise Direction)

selected for the study. Inner Ring Road is around $55 \mathrm{~km}$ long circular road that encircles important locations of the city and is in fact one of the longest roads in Delhi. It starts from the Interstate Bus Terminal (ISBT) at Kashmiri Gate and touches Delhi Gate, ITO, Ashram, AIIMS, Dhaulakuan and Naraina in one semi- circle. On the other half, it passes through Raja Garden, Punjabi Bagh, Azadpur and Delhi University before ending at ISBT. This road is divided in to 27 road segments for data collection and analysis purposes.

\section{Data Collection}

Video recording was done for capturing the traffic flow characteristics, which includes traffic flow, traffic composition, and passage times or travel times of individual vehicles through the study segments. All the collected data was analyzed in laboratory manually to extract the required input values for the measurement of free speed. Traffic flow was determined by counting the number of vehicles passing the entry and exit sections of the study stretch from all the three lanes at every five minute interval and expressed as flow rate. Travel time taken by individual vehicles over a trap length $(50 \mathrm{~m})$ at every five-minute interval were extracted. Travel times and based on known distance, average space mean speeds of vehicles are computed. The location selected for the study are as follows (Fig. 1); Maharani Bagh, towards Sarai kale Khan (LID4), SunLight Colony, towards Ashram Chowk (LID5), MothiBagh, towards Dhaulakuan (LID6), Wazirpur Depot, towards Azadpur (LID7), and Premwadi pool, towards Punjabi Bagh (LID8). The free flow speed can also collected using the Global Positioning System (GPS) instrument (Bekhor et al. 2013). The period of the data collection for free speed at the above mentioned locations are four hours (04 am to $08 \mathrm{am}$ ) for two days and the GPS data on entire corridor is collected for one week by different modes (Car, Bus and Three Wheeler) covering the different peaks on working days and holidays.

\section{Traffic Characteristics under Free Flow Conditions}

The data collected for all the locations was utilized in the free speed analysis. The category wise analysis is presented in detail in the following sections.

\subsection{Traffic Variations}

The traffic stream on study corridor consists of different vehicle types present in the heterogeneous traffic and hence all the vehicle types are grouped into eight different categories for the purpose of this study. The vehicular types are as follows; Cars (New and Old technology cars, Jeeps), Buses, Two-Wheelers (TW) (Motorcycles, Scooters and all other types of two wheelers), Three-wheelers (THW) (Auto-Rickshaws of passengers and goods), Light Commercial Vehicles (LCV), Trucks and 
Bicycle and Cycle Rickshaws. The flow characteristics (total volume, traffic composition) observed at one typical location (LID 8) are presented in Fig. 2. The free flow speed observations are given in Table 1.

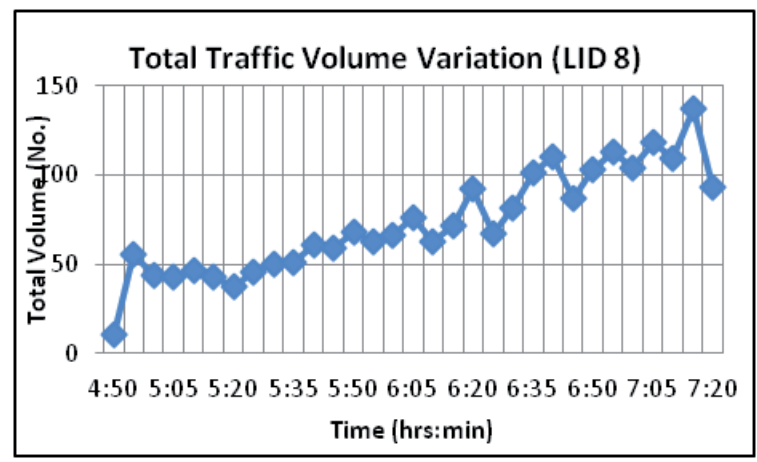

Traffic Composition \% (LID 8)

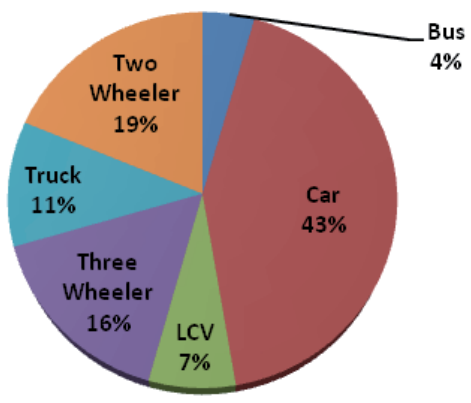

Fig. 2 Traffic characteristics at typical location during free flow conditions (LID 8)

Table 1 Free Speed Observed at LID 8

\begin{tabular}{|c|c|c|c|c|c|c|c|}
\hline Time & $\cong$ & U் & 己̇ & in & 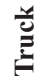 & i & $\begin{array}{c}\text { Avg. Speed } \\
(\mathrm{km} / \mathrm{h})\end{array}$ \\
\hline $4: 50$ to $4: 55$ & 37 & 55 & 36 & 36 & 45 & & 41.9 \\
\hline $4: 55$ to $5: 00$ & & 52 & 50 & 40 & 44 & 58 & 49.1 \\
\hline $5: 00$ to $5: 05$ & 60 & 56 & 50 & 36 & 49 & 42 & 49.1 \\
\hline $5: 05$ to $5: 10$ & & 62 & 55 & 54 & 55 & 49 & 55.1 \\
\hline $5: 10$ to $5: 15$ & 30 & 70 & 70 & 45 & 50 & 47 & 52 \\
\hline $5: 15$ to $5: 20$ & & 59 & 45 & 75 & 52 & 45 & 55.2 \\
\hline $5: 20$ to $5: 25$ & 52 & 57 & 45 & 45 & 49 & 58 & 51.3 \\
\hline $5: 25$ to $5: 30$ & & 58 & 53 & 37 & 52 & 40 & 48.2 \\
\hline $5: 30$ to $5: 35$ & 60 & 63 & 60 & 45 & 56 & 54 & 56.4 \\
\hline $5: 35$ to $5: 40$ & 60 & 62 & 62 & 40 & 53 & 54 & 60.3 \\
\hline $5: 40$ to $5: 45$ & 45 & 64 & 47 & 38 & 49 & 40 & 47.1 \\
\hline $5: 45$ to $5: 50$ & & 62 & 42 & 42 & 55 & 65 & 53.6 \\
\hline $5: 50$ to $5: 55$ & 45 & 63 & 51 & 39 & 51 & 51 & 50.1 \\
\hline $5: 55$ to $6: 00$ & 60 & 68 & 41 & 43 & 55 & 53 & 53.6 \\
\hline $6: 00$ to $6: 05$ & 47 & 65 & 60 & 44 & 52 & 52 & 53.6 \\
\hline Average & 50 & 62 & 48 & 43 & 48 & 52 & 50.8 \\
\hline
\end{tabular}

\subsection{Speed Distributions}

Speed distribution is an arrangement of speed values showing their observed or theoretical frequency of occurrence. Different drivers select different speeds, dependent upon many variables such as speed limit (Deardoff et al., 2011; Cho and Kim, 2012), vehicle limitations, roadway conditions, driver ability, etc.. No single speed data point can accurately represent all the speeds at a particular location. Operating speeds have found to be normally distributed. Free-speed data collected at five locations (11089 vehicles, Table 4) was also analysed by fitting normal distribution.

A typical speed distribution observed for light motor vehicles along with the expected distribution is plotted (Fig. 3 and 4). From the speed distributions observed the characteristics such as namely 15 th percentile speed $(V 15)$, 50th percentile speed (V50), 85th percentile speed (V85), 95th percentile speed (V95) calculated separately for each mode and presented in Table 2. The percentile speeds are helpful in determining the goodness of the fit of the normal distribution and also they help in understanding characteristics of the vehicles like design speed, fixation of maximum and minimum speed limits and speed characteristics of the stream. Spread Ratio (SR) is calculated to check the validity of the data (Dey et al., 2006). SR is used to explain normality of the observed data and it is computed using the formula;

$$
S R=\left(v_{85}-v_{50}\right) /\left(v_{50}-v_{15}\right)
$$

The estimated frequency curve will be truly normal when $\mathrm{SR}$ is unity. It will tend to deviate from the normal distribution as SR deviates from the unity. From Fig. 3 and 4 it can be observed that the observed speed was following the estimated speed. The speed data follows the normal distribution for SR ranging between 0.69 and 1.35 (Dey et al., 2006). In the present study the SR was found to be 0.99 . In order to further ascertain this distribution, chi-square test was performed.

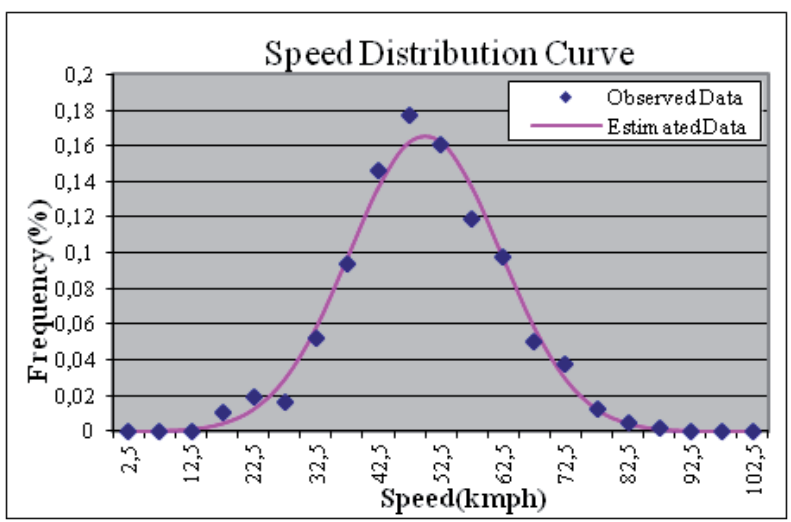

Fig. 3 Speed Distribution for car 


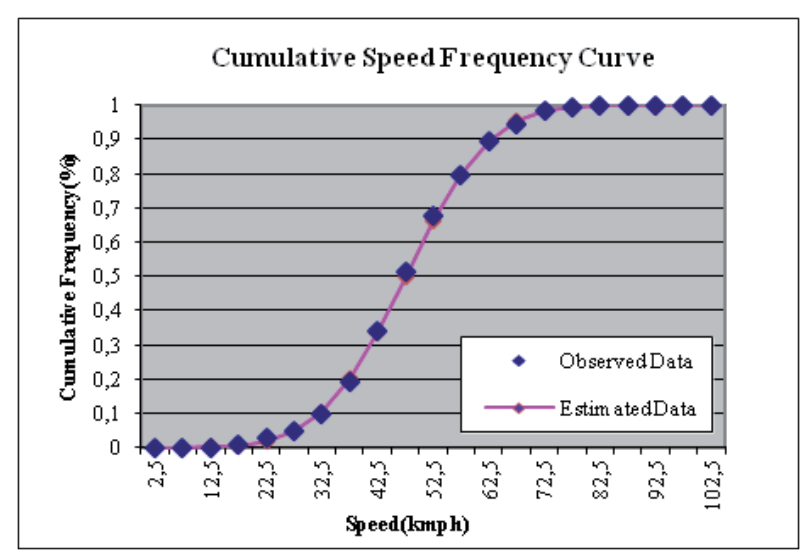

Fig. 4 Cumulative speed distribution for car

\subsection{Free Speed Profile}

Speed profiles are graphical representation of speed characteristics for each location. Speed profiles are useful for study and evaluation of the traffic characteristics. The observed space mean speeds (free flow conditions) of different vehicle types were classified into suitable intervals $(5 \mathrm{~km} / \mathrm{h})$ to determine the frequency distribution of vehicles as per speed. The mean and standard deviation values were calculated from the frequency distributions. The characteristics namely $15^{\text {th }}$ percentile speed (V15), $50^{\text {th }}$ percentile speed (V50), $85^{\text {th }}$ percentile speed (V85), $95^{\text {th }}$ percentile speed (V95), mean, minimum, maximum, standard deviation and coefficient of variance were calculated for different locations. The percentile speeds and cumulative percentile speed graphs are prepared for all types of modes. The summary of the percentile speed observed at all locations are shown in Table 2. It can be seen that speeds of all types of vehicles are similar (around $40 \mathrm{~km} / \mathrm{h}$ ) for 50 th and 85 th percentile ranges. Whereas cars and 2W's show a high 95th percentile speed, which is at least $30 \mathrm{~km} / \mathrm{h}$ higher than other vehicle types.

Table 2 Mode Wise Percentile Speeds

\begin{tabular}{ccccccc}
\hline Percentile Speeds/Mode & Bus & Car & LCV & 3W & Truck & 2W \\
\hline 15 & 30 & 39 & 35 & 34 & 34 & 39 \\
50 & 40 & 45 & 41 & 41 & 41 & 44 \\
85 & 61 & 64 & 63 & 61 & 64 & 64 \\
95 & 65 & 88 & 65 & 65 & 65 & 86 \\
\hline
\end{tabular}

\section{Free Flow Speed (FFS) from Field Measurement}

Videos are analysed to convert passage times into travel times and eventually into speeds. Thereafter, the speed data were inspected for each site to ascertain the existence of any outliers or other unusual values. Such inspection was important for all data types for further analysis. Histograms of speed data were prepared for all the sites. The resulting histograms were inspected to ensure that all outliers were investigated so that the final speed distributions were acceptable. When retrieving data from the video some were found. These are the vehicles that did not stop but travelled slowly. Free-speed analysis mainly focuses on free-flow conditions, hence the vehicles travelling with higher speeds are considered normal while arriving at the average free-speeds. Thus, the slow moving vehicles considered as outliers can be dispensed with. The lower speeds considered as outliers are as follows; bus and truck $20 \mathrm{~km} / \mathrm{h}, \mathrm{LCV}$, 2W and $3 \mathrm{~W} 30 \mathrm{~km} / \mathrm{h}$ and car $40 \mathrm{~km} / \mathrm{h}$ (Ponnu et al. 2013). The free speed characteristics such as mean, minimum, maximum, standard deviation and Coefficient of Variance (CV) are computed for all the locations are presented in Table 3. From this table it is evident that cars have highest while buses have lowest free flow speeds in the observed data set.

Table 3 Free Speed Characteristics of Different Types of Vehicles (all Locaions)

\begin{tabular}{|c|c|c|c|c|c|}
\hline \multirow[b]{2}{*}{ 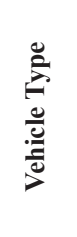 } & \multicolumn{5}{|c|}{ Free speed characteristics $(\mathrm{km} / \mathrm{h})$} \\
\hline & 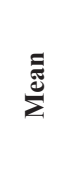 & 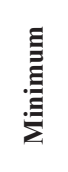 & 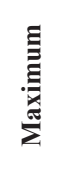 & 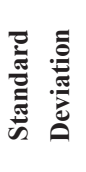 & 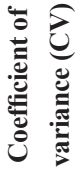 \\
\hline Bus & 41.3 & 20.0 & 60.0 & 10.7 & 0.260 \\
\hline Car & 58.9 & 45.0 & 90.0 & 14.7 & 0.248 \\
\hline $\mathrm{LCV}$ & 45.7 & 30.0 & 70.0 & 10.7 & 0.234 \\
\hline $3 \mathrm{~W}$ & 43.8 & 30.0 & 60.0 & 9.3 & 0.211 \\
\hline Truck & 45.2 & 20.0 & 70.0 & 12.9 & 0.285 \\
\hline $2 \mathrm{~W}$ & 51.6 & 30.0 & 90.0 & 15.0 & 0.290 \\
\hline
\end{tabular}

In order to consider sample size which is a significant for quality of outputs, statistical tests were carried-out to ascertain the adequacy of the sample size. Simplified formula at $95 \%$ confidence interval to calculate sample size is given below (Yamane, 1967);

$$
n=\frac{N}{1+N(e)^{2}}
$$

where

$$
\begin{aligned}
& \mathrm{n} \text { - Sample size } \\
& \mathrm{N} \text { - Population size } \\
& \mathrm{e} \text { - Desired level of precision }
\end{aligned}
$$

Using the above formula for the total population size of 23,387 at error level 5\%, the required samples are 393 . In the present study we collected the data for about 11,089 vehicles, it consists about $46 \%$ of sample size for the chosen confidence interval, and it is greater than the required sample size. The survey of actual number of data collection samples and the sample size are shown in Table 4. 
Table 4 Sample Size at Various Locations for Free Flow Speed

\begin{tabular}{|c|c|c|c|c|c|c|c|c|c|}
\hline \multirow[b]{2}{*}{ } & \multicolumn{7}{|c|}{ Sample Size } & \multirow[b]{2}{*}{ 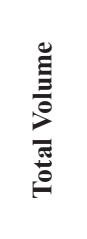 } & \multirow[b]{2}{*}{ 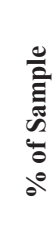 } \\
\hline & $\cong$ & نี & 己 & m & Ẽ & i & 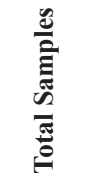 & & \\
\hline $\begin{array}{c}\text { LID } \\
7\end{array}$ & 71 & 566 & 134 & 146 & 135 & 161 & 1213 & 1363 & 89 \\
\hline $\begin{array}{c}\text { LID } \\
4\end{array}$ & 147 & 986 & 211 & 398 & 302 & 494 & 2538 & 6026 & 42.1 \\
\hline $\begin{array}{c}\text { LID } \\
6\end{array}$ & 80 & 481 & 89 & 120 & 199 & 196 & 1165 & 2718 & 42.9 \\
\hline $\begin{array}{c}\text { LID } \\
5\end{array}$ & 633 & 1441 & 296 & 586 & 286 & 835 & 4077 & 8734 & 46.7 \\
\hline $\begin{array}{c}\text { LID } \\
8\end{array}$ & 54 & 913 & 152 & 325 & 242 & 410 & 2096 & 4546 & 46.1 \\
\hline Total & 985 & 4387 & 882 & 1575 & 1164 & 2096 & 11089 & 23387 & 47.4 \\
\hline
\end{tabular}

The summary of results based on free-speed analysis for different vehicles are presented in Table 5.

Table 5 Average Free Speed $(\mathrm{km} / \mathrm{h})$ at Various Locations

\begin{tabular}{|c|c|c|c|c|c|c|c|}
\hline : & $\stackrel{\mathscr{A}}{\mathscr{A}}$ & 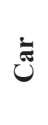 & 己త & m & 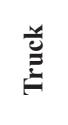 & i & 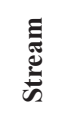 \\
\hline LID 7 & 37 & 64 & 45.6 & 44 & 42.4 & 54 & 47.6 \\
\hline LID 4 & 43 & 54 & 44.5 & 47 & 42.6 & 48 & 46.6 \\
\hline LID 6 & 49 & 61 & 52.4 & 52 & 51.7 & 59 & 54.2 \\
\hline LID 5 & 40 & 57 & 44 & 44 & 42.3 & 51 & 46.3 \\
\hline LID 8 & 43 & 63 & 47.1 & 43 & 48.2 & 53 & 48.7 \\
\hline Avg. Speed & 43 & 60 & 46.7 & 46 & 45.4 & 53 & 48.7 \\
\hline
\end{tabular}

\subsection{Comparison of Free Speeds}

The free speed for similar facility after taking the speed limit, median type and access points density etc. as per the US HCM 2010 is around $60 \mathrm{~km} / \mathrm{h}$ (Geistefeldt, 2011). These values are higher than those in the present studyarea. This reduction of free speed may be due to the road environment and traffic conditions. The free speed observed in Indonesia for one-way three lane urban roads for very high friction level is $50 \mathrm{~km} / \mathrm{h}$ for city population exceeding 3 million, presents Study the level of friction is very high, and the results observed through study are near to the Indonesia traffic stream, the traffic pattern of Indonesia and India are the similar. The results of individual vehicle free speeds are compared with those in in China HCM. vehicles fleet on similar vehicle types and facilities after applying the adjustment factors, Bus speed was found to be 42.5 $\mathrm{km} / \mathrm{h}$ from this study and the corresponding value is $49 \mathrm{~km} / \mathrm{h}$ as per China HCM. Light Commercial Vehicles (LCV) $46.7 \mathrm{~km} / \mathrm{h}$,
China LCV $49 \mathrm{~km} / \mathrm{h}$, Three Wheeler $45.8 \mathrm{~km} / \mathrm{h}$, China Three Wheeler $45 \mathrm{~km} / \mathrm{h}$, Truck $45.4 \mathrm{~km} / \mathrm{h}$, China Truck $44 \mathrm{~km} / \mathrm{h}$, Car $59.7 \mathrm{~km} / \mathrm{h}$, China car $45 \mathrm{~km} / \mathrm{h}$, Mini vehicles class combines the three-axle mc and small cars this may be reason for large difference in free speed). From the above results observed from the field studies seems to be reasonable agreement on free flow conditions on the arterial roads in Delhi.

\section{Factors Affecting the Free Speed}

The roadside activities affect the operation of traffic stream and may cause delay and these activities affect the free speed on the road sections. HCM-2010 considers the road side environment and consequent friction to the traffic to be important factor which influences the free speed (HCM, 2010; Brilon, Lohoff, 2011). Indonesian HCM considered the side friction classes and the city size effects on the free speed of the vehicles (IHCM, 1993). Vehicle weights also have influence on free flow speed (Saifizul et al., 2011). After studying both the HCMs and other literature the following factors were identified which are likely to influence the free flow speed. The factors are:

1. Lane Width and Lateral Clearance

2. Median Type

3. Access Points

4. Carriageway Width

5. Roadside Environment

6. Side Friction Class

7. City size

Some of these factors are discussed here.

\subsection{Lane Width and Lateral Clearance}

HCM proposed lane width and lateral clearance adjustments; these two adjustments reflect the effect of a constricted cross section on free-flow speeds. The adjustments relate to the average width of lanes and the combined lateral clearance along the right side and the median of a multilane highway. Lane widths less than $3.6 \mathrm{~m}$ reduce travel speeds; however, widths of more than $3.6 \mathrm{~m}$ are not considered to increase speed above the base level. For lateral clearance, a total clearance that is, the left side plus the right side along one direction of roadway of $3.6 \mathrm{~m}$ or more is considered as the base condition. A combined lateral clearance of less than $3.6 \mathrm{~m}$ has a negative influence on travel speeds (HCM, 2010).

\subsection{Access Points}

An important influence on FFS is the number of access points along the left side of the roadway. The amount of activity at each point contributes to changes in travel speed, typically, only access points on the left of the roadway are taken into account. Intersections, median openings on the opposite side that are expected to have a significant effect on traffic flow in the direction of interest may be included when determining accesspoint density. The data indicates that for each access point per 
kilometer the estimated FFS decreases by approximately 0.4 $\mathrm{km} / \mathrm{h}$, regardless of the type of median. Access points unnoticed by the driver or with little activity should not be included in determining access-point density (HCM, 2010).

\subsection{Environment and side friction}

Roadside environment and activities often conflict, sometimes severely, with the traffic flow. The effects of these conflicts, ("side friction") should be considered while calculating free speed and capacity. The following side-friction items have been found to affect traffic significantly on urban roads; (IHCM, 1993)

- Pedestrians walking

- Stopping vehicles on pavement

- Non-motorized vehicle movements on the road

- Pedestrians crossing the road

- Vehicles entering and leaving roadside premises

- Parking on roadway or shoulder

\subsection{City Size}

Free speed varies according to the size of the city, because the driver behavior and traffic characteristics fully depend on the size of the city. The city size can be defined in to various classes based on the inhabitants in the city, example small: Inhabitants $<0.5$ millions, Medium: 0.5 to 1.0, Large: 1 to 3, and Very large: more than 3 millions. In this study, this parameter is not considered, because the study area is only one city (IHCM, 1993).

\subsection{Friction Points in Study Area}

The all the characteristics mentioned above are considered for the model development for free flow condition, an attempt is made to incorporate the characteristics which effect the free flow are listed in the Table 6.

Table 6 Friction Classes Considered in the Study (IHCM, 1993)

\begin{tabular}{|c|c|c|c|}
\hline S.No. & Friction Item & Description & Input Type \\
\hline 1 & Friction point & $\begin{array}{c}\text { Bus stop } \\
\text { Intersection type } \\
\text { Flyover } \\
\text { Petrol pump } \\
\text { Pedestrian crossing } \\
\text { Number of lanes }\end{array}$ & $\begin{array}{c}\text { Total number } \\
\text { of frictions }\end{array}$ \\
\hline 2 & Pedestrian movement & $\begin{array}{c}\text { Low } \\
\text { High } \\
\text { Medium }\end{array}$ & Qualitative \\
\hline 3 & $\begin{array}{c}\text { Vehicles stopping on } \\
\text { road }\end{array}$ & $\begin{array}{c}\text { Low } \\
\text { High } \\
\text { Medium }\end{array}$ & Qualitative \\
\hline 4 & $\begin{array}{l}\text { Vehicle turning and exit } \\
\text { from section }\end{array}$ & $\begin{array}{c}\text { Access points } \\
\text { Median opening }\end{array}$ & Total number \\
\hline
\end{tabular}

\section{Free Speed Modeling}

An attempt was made in this study to model the free flow speed by considering the traffic characteristics (Transportation Research Board, 2011; Luca et al., 2012) and road geometrics and (Mingjun et al., 2007).

\subsection{Regression Analysis}

The models were developed for each individual site and the performance of the model is evaluated for each site. Regression analysis is carried out using all the traffic composition and the total number of vehicles, the variables such as friction points, pedestrian movement, and vehicle stopping on road, access points, and length of section were not considered at individual level because these values are constant. The models were developed for individual sites, the summary of the models i.e. $\mathrm{R}^{2}$ values are given in Table 7.

Table 7 Summary of the Models for Individual Sites

\begin{tabular}{cc}
\hline Location & $\mathbf{R}^{2}$ Values \\
\hline LID 7 & 0.55 \\
LID 4 & 0.68 \\
LID 6 & 0.57 \\
LID 5 & 0.72 \\
LID 8 & 0.47 \\
\hline
\end{tabular}

Table 8 Performance of various Regression Models

\begin{tabular}{|c|c|c|}
\hline Model & Characteristics & $\begin{array}{c}\text { Performance of } \\
\text { Model }\end{array}$ \\
\hline \multirow{3}{*}{ HCM (2010) } & Speed Limit & \multirow{3}{*}{$\mathrm{R}^{2}=0.16$} \\
\hline & $\begin{array}{c}\text { Carriageway Width } \\
\text { Access points }\end{array}$ & \\
\hline & Length & \\
\hline \multirow{3}{*}{ Indonesia $\mathrm{HCM}$} & Carriageway Width & \multirow{3}{*}{$\mathrm{R}^{2}=0.124$} \\
\hline & $\begin{array}{l}\text { Pedestrian movements } \\
\text { IPT Stopping on road }\end{array}$ & \\
\hline & Access points & \\
\hline \multirow{3}{*}{ China HCM } & Carriageway Width & \multirow{3}{*}{$\mathrm{R}^{2}=0.021$} \\
\hline & $\begin{array}{l}\text { Road Class } \\
\text { Side Friction }\end{array}$ & \\
\hline & Road Side Development & \\
\hline \multirow{5}{*}{ Present Study } & Total Vehicles & \multirow{5}{*}{$\mathrm{R}^{2}=0.541$} \\
\hline & Friction Points & \\
\hline & $\begin{array}{c}\text { Major Intersections } \\
\text { Flyovers }\end{array}$ & \\
\hline & Access points & \\
\hline & Length & \\
\hline
\end{tabular}


Table 9 Summary of Regression Analysis

\begin{tabular}{ccccc}
\hline \multicolumn{5}{c}{ Model Summary } \\
\hline Model & R & R Square & Adjusted R Square & Std. Error of the Estimate \\
\hline 1 & $.735^{\mathrm{a}}$ & .541 & .513 & 3.372794 \\
\hline
\end{tabular}

\begin{tabular}{|c|c|c|c|c|c|c|}
\hline \multicolumn{7}{|c|}{ ANOVA $^{b}$} \\
\hline & Model & Sum of Squares & df & Mean Square & $\mathbf{F}$ & Sig. \\
\hline \multirow{3}{*}{1} & Regression & 1339.333 & 6 & 223.222 & 19.623 & $.000^{\mathrm{a}}$ \\
\hline & Residual & 1137.574 & 100 & 11.376 & & \\
\hline & Total & 2476.907 & 106 & & & \\
\hline
\end{tabular}

\begin{tabular}{|c|c|c|c|c|c|c|}
\hline \multicolumn{7}{|c|}{ Coefficients $^{\mathrm{a}}$} \\
\hline & \multirow{2}{*}{$\begin{array}{c}\text { Model } \\
\text { B }\end{array}$} & \multicolumn{2}{|c|}{ Unstandardized Coefficients } & \multirow[t]{2}{*}{$\begin{array}{c}\text { Standardized } \\
\text { Coefficients }\end{array}$} & \multirow[t]{2}{*}{$\mathbf{t}$} & \multirow[t]{2}{*}{ Sig. } \\
\hline & & Std. Error & Beta & & & \\
\hline \multirow{7}{*}{1} & (Constant) & 67.785 & 3.307 & & 20.494 & .000 \\
\hline & 1. Total Vehicles & -.040 & .007 & -.614 & -5.416 & .000 \\
\hline & 2. Number of Friction Points & -.051 & .209 & -.052 & -.243 & .809 \\
\hline & 3. Major Intersections & -3.593 & 1.370 & -.854 & -2.623 & .010 \\
\hline & 4. Number of Flyovers & 1.070 & 2.622 & .093 & .408 & .684 \\
\hline & 5. Access Points & 1.993 & .355 & 2.022 & 5.620 & .000 \\
\hline & 6. Length of the Section & -5.744 & .928 & -2.101 & -6.192 & .000 \\
\hline
\end{tabular}

a. Dependent Variable: Free Speed

From the results (Table 9), at most of the sites regression models are performing well, hence same technique can be used for development of aggregate models so the one can use these models across the study area.

\subsection{Aggregate Level Models}

The models developed in the above section can be used only for individual sites. Since they were not the common models and common models can help to predict the free speed across the study area, the common models (aggregate models) were developed by using the regression techniques. The entire datas collected at all the sites are combined together therefore, an aggregate level model is developed. The regression models are developed using the characteristics suggested by various HCM. An attempt was made to model the free speed combining the characteristics across the HCMs. The performance of the regression models are given in Table 8 .

From the Table 8, it can be inferred that the performance of the regression models based on the various HCMs are not up to the mark. After several combinations, the present study observed the performance of the model is good for the listed characteristics. The summary of the present study model and the statistical test results such as $\mathrm{R}^{2}$, ANOVA test results are given in Table 9.
The aggregate models are developed for free speed of traffic, and they can be used to predict the free speed at any location on the study corridor. The model developed under the study is given below;

$$
Y=a_{1} X_{1}+a_{2} X_{2}+a_{3} X_{3}+a_{4} X_{4}+a_{5} X_{5}+a_{6} X_{6}+C
$$

where

$\mathrm{C}=$ Constant

$X_{1}=$ Total no. of Vehicles, $X_{2}=$ Friction Points, $X_{3}=$ Number of Major Intersections, $\mathrm{X}_{4}=$ Number of flyover, $\mathrm{X}_{5}=$ Access Points and X6 = Length of the section

The values of $a_{1}$ to $a_{6}$ are given in the.

\section{Summary and Conclusions}

Free speed modelling on urban arterials depends on various factors (traffic, road environment and geographic context). The factors which are found to have significant influence are road side friction, number of flyovers, access points and length of the section under consideration. The following are the conclusions based on the study.

- The traffic composition observed during free flow conditions are Car 43\%; LCV 7\%, Three Wheeler 16\%, Truck $11 \%$, Two Wheeler $19 \%$ and Bus $4 \%$, the composition 
of traffic in normal conditions are different from this (the normal conditions typically have Cars: 55\%, threewheeler 7\%, Truck +LCV 5\%, Buses 3.5\%).

- The operating speeds under free flow conditions on the study corridor have been observed as normally distributed.

- The free speeds of different vehicles observed are Bus $42.5 \mathrm{~km} / \mathrm{h}$, Car $59.7 \mathrm{~km} / \mathrm{h}$, LCV $46.7 \mathrm{~km} / \mathrm{h}$, Three wheeler $45.8 \mathrm{~km} / \mathrm{h}$, Truck $45.4 \mathrm{~km} / \mathrm{h}$ and Two wheeler 53.0 $\mathrm{km} / \mathrm{h}$ and the average stream free flow speed observed is $48.7 \mathrm{~km} / \mathrm{h}$.

- The variables such as composition of the vehicles, length of the segment length do not seem to have significant influence on the free flow speeds.

- The factors like total vehicles, friction points, access points, number of intersection, number of flyovers and access points have significant contribution of free speed. Regression model has been developed for free flow estimation for urban arterial, this model can be used to estimation of free flow speed.

- The model has a prediction ability which is restricted to the arterial on which the data was collected. Further extensive studies needs to be done in order to make the results more robust in terms of consideration of the land use and road types.

\section{Acknowledgements}

One of the authors (AMR) wishes to thank, Dr. S. Gangopadhyay, Director, Central Road Research Institute, New Delhi, India for their permission to publish this paper

\section{References}

Baruzzi, A. Galarraga, J., Herz, M. (2008) Effects of Grades and Visibility on Freeway Free Flow Speeds. Traffic and Transportation Studies Congress. DOI: 10.1061/40995(322)90

Bassani, M., Sacchi, E. (2012) Calibration to Local Conditions of Geometrybased Operating Speed Models for Urban Arterials and Collectors. Procedia - Social and Behavioral Sciences. 53. pp. 821-832. DOI: 10.1016/j.sbspro.2012.09.931

Bekhor, S., Lotan, T., Gitelman, V., Morik, S. (2013) Free-Flow Travel Speed Analysis and Monitoring at the National Level Using Global Positioning System Measurements. Journal of Transportation Engineering. 139 (12). pp. 1235-1243. DOI: 10.1061/(ASCE)TE.1943-5436.0000607

Brilon, W., Lohoff, J. (2011) Speed-flow Models for Freeways. Procedia - Social and Behavioral Sciences. 16. pp. 26-36. DOI: 10.1016/j.sbspro.2011.04.426

CHCM (1996) China Highway Capacity Manual. National Highway Project of the People's Republic of China.

Cho, H., Kim, Y. (2012) Analysis of Traffic Flow with Variable Speed Limit on Highways. KSCE Journal of Civil Engineering. 16 (6). pp. 1048-1056. DOI 10.1007/s12205-012-1395-x

Deardoff, M. D., Wiesner, B. N., Fazio, J. (2011) Estimating Free-flow Speed from Posted Speed Limit Signs. Procedia - Social and Behavioral Sciences. 16. pp. 306-316. DOI: 10.1016/j.sbspro.2011.04.452
Dey, P. P., Chandra, S., Gangopadhya, S. (2006) Speed Distribution Curves under Mixed Traffic. Journal of Transportation Engineering. 132 (6). pp. 475-491. DOI: 10.1061/(ASCE)0733-947X(2006)132:6(475)

Dowling, R., Kittelson, W., Zegeer, J., Skabardonis, A. (1997) Planning Techniques to Estimate Speeds and Service Volumes for Planning Applications. NCHRP Report 387,Transportation Research Board. pp. 12-15

Economic Survey of Delhi (2012) Economic Survey of Delhi- Transport. [Online] Available from: http://delhi.gov.in/DoIT/DoIT_Planning/ES2012-13/EN/ ES_chapter12.pdf [Accessed: July 2013]

Fazio, J. Wiesner, B. N., Deardoff, M. D. (2014) Estimation of Free-Flow Speed. KSCE Journal of Civil Engineering. 18 (2). pp. 646-650. DOI: $10.1007 / \mathrm{s} 12205-014-0481-7$

Geistefeldt, J. (2011) Capacity effects of variable speed limits on German freeways. Procedia - Social and Behavioral Sciences. 16.p. 48-56. DOI: $10.1016 /$ j.sbspro.2011.04.428

HCM (2010) Highway Capacity Manual 2010. Transportation Research Board. Lamm, R., Choueiri, E. M., Mailaender, T. (1990) Comparison of Operating Speeds on Dry and Wet Pavements of Two-Lane Rural Highways. Transportation Research Record.

Luca, M. D., Lamberti, R., Dell'Acqua, G. (2012) Freeway Free Flow Speed: a case study in Italy. Procedia - Social and Behavioral Sciences. 54 (4). pp. 628-636. DOI: 10.1016/j.sbspro.2012.09.780

Mingjun, L., Keping, L., Xiaohui, D., Kaiying, W.(2007) Implementation and Validity of the Free Flow Speed Model of on Freeway. International Conference on Transportation Engineering. pp. 3452-3457. DOI: $10.1061 / 40932(246) 566$

Ng, C. F., Small, K. A. (2012) Tradeoffs among free-flow speed, capacity, cost and environmental footprint in highway design. Transportation. 39 (6). pp. 1259-1280. DOI 10.1007/s11116-012-9395-8

Ponnu, B., Thomas, J., Jha, K., Asaithambi, G., Srinivasan, K. K. (2013) Vehicle Class-wise speed volume model for three-lane undivided urban roads. Procedia - Social and Behavioral Sciences. 104. pp. 468-476. DOI: $10.1016 /$ j.sbspro.2013.11.140

Saifizul, A. A., Yamanaka, H., Karim, M. R. (2011) Empirical analysis of gross vehicle weight and free flow speed and consideration on its relation with differential speed limit. Accident Analysis and Prevention. 43 (3). pp. 1068-1073. DOI: 10.1016/j.aap.2010.12.013

Polgár, J., Tettamanti, T., Varga, I. (2013) Passenger number dependent traffic control in signalized intersections. Periodica Polytechnica Civil Engineering. 57 (2). pp. 201-210. DOI: 10.3311/PPci.7175

Tettamanti, T., Varga, I. (2014) Mobile phone location area based traffic flow estimation in urban road traffic. Advances in Civil and Environmental Engineering. 1 (1). pp. 1-15.

Török, Á. (2013) Simplification of Road Transport Infrastructure Layout for Better Self-Explanation. American Journal of Vehicle Design. 1 (1). pp. 16-20. DOI: 10.12691/ajvd-1-1-3

Transportation Research Board (2011) Modeling Operating Speed. Transportation Research Circular. Number E-C151.

Tseng, P-Y., Lin, F-B., Chang, C-W. (2013) Analysis of free-flow speed characteristics on urban arterials. Asian Transport Studies. 2 (4). pp. 363-378. DOI: $10.11175 /$ eastsats.2.363

Wang, T., Harvey, J., Lea, J., Kim, C. (2014) Impact of Pavement Roughness on Vehicle Free-Flow Speed. Journal of Transportation Engineering. 140 (9). 04014039. DOI: 10.1061/(ASCE)TE.1943-5436.0000689

Yamane, T. (1967) Statistics: An introductory analysis. Harper and Row. 